\title{
Religious (Islamic) Culture Pluralism to Wittgenstein and Gadamer (A Comparative Study)
}

\author{
Seyed Amirreza Mazari \\ Islamic Azad University
}

\begin{abstract}
The current study aims to explain the fundamentals of religious pluralism in Wittgenstein later philosophy and Gadamer philosophical hermeneutics, specifically regarding culture. It, then, proposes the approach more suitable for the Islamic context. Having fulfilled such an objective, pluralism, concerning religious rituals, becomes accepted and cultural and religious interaction is realized without any relativism conclusion. Wittgenstein's pluralism results in pure relativism. That is to say, in order to understand the rules of the language game and life style he mentions, one needs to be placed inside. However, it is a dialectical model that Gadamer philosophical hermeneutics leads to. Dialogue gives opportunity to cultural interaction and convergence, developing the religious culture. The latter is of more proximity to Islamic resources such as the Quran, proposing a religious culture transcending cultural, historical, and social limitations. All in all, the two significant features of Gadamer's which Wittgenstein ignores are first, the interaction of religious pluralism encouraging the development of religious culture and second, reciprocal relation between culture and religion based on hermeneutics circle.
\end{abstract}

Keywords: religious culture, language game and Gadamer philosophical hermeneutics

\section{Introduction}

As one of the two major philosophers of the 20th century, Wittgenstein has left a significant effect on critical philosophy. The multiple interpretations of his both early and late philosophies suggest his significance. On the other hand, Heidegger, the other prominent philosophical figure of that era, trained scholars who have followed him in various fields of philosophy and theology. The one who presented Heidegger's philosophical hermeneutics to the world, Gadamer, took revolutionary steps in hermeneutics. While drawing a comparison between Wittgenstein and Gadamer may initially seem irrelevant since they focused their efforts into two distinct categories of thought, critical and continental philosophy respectively; the contribution the latter has hypothetically made to the thoughts of the former acts as the motive to investigate the key role language plays in culture and the creation of a religious culture ever-developing. Studying these two figures in the Islamic context seems an appropriate way to test these effects.

\section{Wittgenstein}

In his Philosophical Investigation (1953), Wittgenstein strongly believes that the meaning of a term is but determined through its function. He is chiefly seeking to show that there is an identity between thought and

Seyed Amirreza Mazari, Ph.D. Candidate, Science and Research Branch, Islamic Azad University, Iran; main research field: Philosophy and Theology. 
language, i.e., thinking is out of question with the absence of language. Thinking, of any kind, thus, takes place under the wing of concepts acquired in the language. What is more, he considers language to be social rather than private.

In his Tractatus Logic - Philophicus (1922), written based on his early philosophy, Wittgenstein refutes the idea of human as a language user. In other words, any meaningful statement is a description of the state of affairs regardless of human as a user. In Tractatus Logic-Philophicus, the structure of language mirrors the structure of the facts and the structure of facts are just reflected in language. But as suggested in Philosophical Investigation (1953), it is the language that determines facts. To think of the world, to speak of the world, needs a system of concepts, stemming from language, to help us do so (Alavinia 1380, 39-40).

Our understanding of the world structured by the concepts language games have developed cannot be achieved otherwise.

Consider, for example, the proceedings that we call "games.” I mean board-games, card-games, ball-games, Olympic Games, and so on. What is common to them all?_-Don't say: “There must be something common, or they would not be called 'games'"-but look and see whether there is anything common to all. For if you look at them you will not see something that is common to all, but similarities, relationships, and a whole series of them at that. To repeat: don't think, but look!-Look for example at board-games, with their multifarious relationships. Now pass to card-games; here you find many correspondences with the first group, but many common features drop out, and others appear. When we pass next to ballgames, much that is common is retained, but much is lost. Are they all "amusing?" Compare chess with noughts and crosses. Or is there always winning and losing, or competition between players? Think of patience. In ball games, there is winning and losing; but when a child throws his ball at the wall and catches it again, this feature has disappeared. Look at the parts played by skill and luck; and at the difference between skill in chess and skill in tennis. Think now of games like ring-a-ring-a-roses; here is the element of amusement, but how many other characteristic features have disappeared! And we can go through the many, many other groups of games in the same way; can see how similarities crop up and disappear (Wittgenstein 1958, 31; s66).

Thus, resorting to the concepts of language games and form of life, Wittgenstein claims that for a large class of cases - though not for all—in which we employ the word "meaning," it can be defined thus: The meaning of a word is its use in the language. And the meaning of a name is sometimes explained by pointing to its bearer (Wittgenstein 1958, 21; s43). Meaning varies according to the function of the word in the form of life, i.e., the meaning of a word in form of life A is X while the same word in form of life B means $\mathrm{Y}$. What he means by form of life is a culture, as a whole and forms of life suggest different cultures.

These differences have roots in the structures by which a meaning is attributed to a word in different forms of life. These structures create various languages in different forms of life. The concept of language games, thus, is understood through the different rules of meaning in different forms. In likening the acquisition of a language to a game Wittgenstein is emphasizing both the absence of a necessary relationship between words and things, undermining designative theories and bringing out an arbitrary dimension to meaning, and the fact that language acquires its signification through social practice (Lawn 2004, 69).

Generally, Wittgenstein adopting these two concepts states that "So you are saying that human agreement decides what is true and what is false?”- -It is what human beings say that is true and false; and they agree in the language they use. That is not agreement in opinions but in form of life (Wittgenstein 1958, 88; s241). 
In likening language to games Wittgenstein draws attention to their practical dimension. Game playing is more than the formal manipulation of rules. Play is rule-governed no doubt but it is, first and foremost, a practical activity. In like fashion linguistic activity is made up of criss-crossing, variegated patterns of usage, underwritten not by a strict logical schema or merely formal procedure but by the habituated regularities of social praxi (Lawn 2004, 72).

Wittgenstein, in other words, refutes private language argument and asserts that meaning is created not in mind, rather in social realm and agreements socially reached and provable. Doing so, he strongly voices criticism of epistemological theories.

According to such a model, each culture possesses its own rules thus differs from others. There is no way of knowing a culture (game) unless through learning its rules. This is of zero possibility without being exposed to it, being placed inside it. The idea of opening a dialogue with a culture is out of question. If game players, language users, experience the ever-developing game, language, how would it be possible for them to reach a common understanding during the passage of time? What common experience would help link past to present? And what is the link between current language games and the games attached to the same culture but detached from the current time? What link can be established between two different language games?

The point lies in the fact that Wittgenstein gives so much relativity to language games that interaction between and contribution to languages disappear.

Language games, if considered inflexible, deteriorate to no more than rules set in advance. The current language games demand a dynamic, consistent, and comprehensive medium through which they would be able to take part in previous and other language games.

All things considered, there seems to be a part in his model missing. There is no room for interaction and dialogue between cultures. Although he highlights the difference between games, and especially language games, he fails to take into account the contributions they can make to each other and thus, spring a surprise on the players. The description Wittgenstein provides about language game is founded on the rules impeding dynamic of the game.

That missing part in Wittgenstein's model, the dynamic aspect of the game, its charming and absorbing power, is compensated in hermeneutic philosophy presented by Gadamer. Play fulfils its purpose only if the player loses himself in play (Gadamer 1975, 102). Playing is more than merely a competition; it is playfulness.

\section{Gadamer}

Hans-Georg Gadamer is considered as the most prominent hermeneutic philosopher in post-Heidegger era. His major work, Truth and Method (1960), taking 20 years to complete, gives a thorough and detailed description of the event of understanding. In this book, he is mainly seeking to describe how understanding basically takes place. He questions Dilthey's scientific approach to human sciences. To Gadamer, it seemed much more appropriate and here he follows Helmholtz to trace the human sciences back to something like tact or an unmethodizable "je ne sais quoi" Helmholtz, not Dilthey, thus becomes the silent partner of hermeneutics because he does more justice to the human sciences' specific way of knowing. In this sense, Truth and Method can be aptly described as a fundamental critique of the obsession with method that typified those concerned with the scientificity of the human sciences (Grondin 1994, 109). The heart of the initial section of Truth and Method thus consists in a "Critique of the Abstraction Inherent in Aesthetic Consciousness." For Truth and Method, the path through aesthetics amounts to a detour, as it were (Grondin 1994, 110). He believes that there 
is a close relation between understanding and criticism of method. Event of understanding is not a subject to a method adopted by a subject. Rather, subjects can merely describe the event and conditions of understanding.

In the search for a more appropriate model of knowledge than methodical science, Gadamer is guided by the experience of art in the first part of truth and method. The artwork not only creates aesthetic enjoyment, it is also a truth experience, Gadamer stresses emphatically. To reduce the work of art to a purely aesthetic matter would be to make common cause with methodical consciousness, which demands a monopoly on the knowledge of truth, which limits it to the scientifically recognizable. No, says Gadamer, you have to realize that art raises a claim to truth and knowledge. This extension of the concept of truth will later make it possible to do more justice to the path of knowledge of the humanities (Grondin 2009, 54).

Gadamer opens his discussion with the concept of game to talk about this encounter with fact. To understand an artistic work is to enter the game. We adopt more the role of a player than a coach and while playing, we become fascinated by the game introducing us to a superior truth.

Taking a game seriously entails belonging to it, and this belonging in turn precludes treating the game as an object. Moreover, in the same process of playing that prevents objectifying the game, players lose their status as subjects. The large drama in which we cannot choose not to play is history. Human beings exist historically (Weinsheimer 1991, 14). Indeed, he makes the foundation of methodical epistemology waver through employing criticism of method and historicity of human existence.

Like other philosophers, Gadamer places the foundation of his category of thought on certain concepts, including tradition, prejudice, horizon, effective history, historically operative consciousness among others some of which are to be briefly explained. It should be noted, however, that some of these concepts share close meanings and some bear no meaning without some others.

The major features of language are its historicity and sociality. In other words, putting our close relation with language on the margin is impossible. This historical social language constitutes a greater whole Gadamer refers to as tradition.

To understanding tradition from within tradition means to be prejudiced. The hermeneutical circle is distinct from linear induction because not only do the parts lead to an understanding of the whole but there must also be an understanding of the whole Gadamer calls a prejudice, a judgment that precedes inquiry. The necessity of such pre-prejudice indicates that understanding is always possible only insofar as understanding has already begun (Weinsheimer 1991, 14).

Tradition has prejudice along. Gadamer believes understanding inevitably takes place through prejudice. Thus, each thought is based on prejudice. According to him, the history of ideas shows that not until the Enlightenment does the concept of prejudice acquire the negative connotation familiar today. Actually "prejudice" means a judgment that is rendered before all the elements that determine a situation have been finally exam (Gadamer 1975, 273).

It probably can be deducted that, given the concepts of tradition and prejudice, no fundamental distinction can be found between the subject and object in the event of understanding. For all occur in their common context of tradition. Understanding is acquired not through subject controlling the object, rather it is what Gadamer refers to as dialogue; a dialogue with and inside tradition.

Understanding is the continuation of the dialogue preceding us, already started. That is how encountering a new meaning, we both create and revise theories; theories on what which yields meaning, theories we have inherited from tradition. 
To understand something means to have related it to ourselves in such a way that we discover in it an answer to our own questions but "our own" in a way that these questions, too, are assimilated into a tradition and metamorphosed by it. Every act of understanding, even self-understanding, is motivated, stimulated by questions that determine in advance the sight lines of understanding. A text is given voice only by reason of the questions that are put to it today. There is no interpretation, no understanding, that does not answer specific questions that prescribe a specific orientation. Unmotivated questions of the kind that positivism desiderates would pertain to no one and consequently be of no cognitive interest. The point is not to exclude the anticipations of meaning implicit in our questions but to foreground them so that the texts that we are trying to understand can answer them all the more clearly. Thus, successful understanding can be described as the effective-historical concretion of the dialectic of question and answer. It is precisely here that we can see the philosophical import of historically effected consciousness. Gadamer himself calls attention to it at the end of the second part of Truth and Method, before he goes on to extend the significance of hermeneutics beyond the boundaries of the human sciences: "The dialectic of question and answer... now permits us to state more exactly what kind of consciousness historically effected consciousness is. For the dialectic of question and answer that we demonstrated makes understanding appear to be a reciprocal relationship of the same kind as conversation.” Understanding is here defined as a relationship and, more exactly, as dialogue. In terms of its form, understanding is less like grasping a concept, a noetic meaning, than like engaging in a dialogue (Grondin 1994, 116-7).

The dialogue Gadamer refers to is strictly linked to another concept, "horizon.” One seeking to understand through dialogue makes an effort to attract the attention of the second part (addressee). Understanding, as previously mentioned, is dialogue-dependent which requires what Gadamer calls "fusion of horizons.” Horizon of understanding is as much capable of changing as the horizon line. This change depends on dialogue. The procedure through which the horizon of the speaker widens is depicted by Gadamer as the dialectic fusion of horizons.

A dialogue in which the text puts questions to the interpreter even as the interpreter puts questions to the text. This dialogue is always possible because both the author of the text and interpreter of it speak a language, whether or not they speak the same one (Weinsheimer 1991, 15).

Moreover, Gadamer's collection of thoughts and philosophical hermeneutics comprises 3 you-I relationships ${ }^{1}$ the third type of which accounts for the main and most desirable to acquire understanding and fact. In this type, past is neither an object to categorize based on attributes and features nor a strange time whose values and doctrines can be shared by another era. The third hermeneutic experience not only makes the dialogue between the previous and existing traditions possible but also reveals the fact that the present language gets to know its facts via this dialogue with the past language. Gadamer refers to this you-I relationship as Historically Operative Consciousness.

The present time is filled with previous effects which cannot be achieved through revision and recreation, rather through contribution, i.e., dialogue. It is crucial to note that historically operative consciousness dialectically takes place.

All in all, there are 2 perspectives lined up with each other; that understanding has a historical nature and that understanding is textual. They, both, share this claim that understanding takes place within the tradition; the one capable of being written, thought, or performed within a linguistic context. Prejudice, horizon, and finally tradition and its subcategories are not dimensions of mind, rather our language elements. 
Fusion of horizons is but the confrontation of the elements of the language involved in the dialogue, questioning, and dialogue and not subjectivity. Fusion occurs across and along the time. It may occur across the cultures where relatively secluded potential speakers come into contact and reach agreement on common meanings.

The relationship of the text and the interpreter is always a "conversation;" the logic of which is the "logic of question and answer.” All these concepts, central to Gadamer's hermeneutics, point to forms of language, which can only be satisfactorily clarified in a treatment of its linguisticality (Figal 2002, 102).

Hence, the second great thesis of Gadamer: Not only is the execution of understanding verbal, but the object of understanding itself is always linguistic (Grondin 2009, 66).

Language is purely historical, i.e., it is a constituent of an ever-developing tradition where previous meanings leave effects on and intermix with present. According to his perspective on language, language is dialogue. It is incomplete and incapable of completion. For meaning possesses a changeable nature due to fluctuations of historical revolutions and ever-developing nature of dialogue.

We share a reciprocal tie with language; we transfer ourselves inside language as much as we find ourselves within it. It is reflective, a mirror where we play and, simultaneously, are played. Due to its incompletion and ever-altering nature, language is utterly historic.

Gadamer bravely states that language is already an expression of being itself. It is not an instrument that we have. Rather, it is about a universal element, in the middle of both being and understanding find: It is the band that merges both originally (Grondin 2009, 67).

Against the primacy of propositional logic, which conceives-or, rather, misconceives understanding as something at our disposal, Gadamer elaborates a logic of question and answer that understands understanding as participation in meaning, a tradition, and ultimately a dialogue. In this dialogue, there are no statements, only questions and answers that call forth new questions in turn. There are no propositions which can be understood exclusively with respect to the content that they present, if one wants to understand them in their truth... Every proposition has presuppositions that it does not express. Only those who think with these presuppositions can really assess the truth of a proposition. I maintain, then, that the ultimate logical form of the presuppositions that motivate every proposition is the question. Here we come to the heart of hermeneutic philosophy-namely, as Gadamer expresses it, "the hermeneutic ur-phenomenon, that there is no possible statement that cannot be understood as the answer to a question, and can only be understood thus” (Grondin 1994, 119).

If, however, Gadamer can maintain that understanding is in principle linguistic, it is because language embodies the sole means for carrying out the conversation that we are and that we hope to convey to each other. It is for this reason that hermeneutics permits itself an aphorism such as "Being that can be understood is language.” The emphasis should be on the "can.” Understanding, itself always linguistically formed and dealing with things verbal, must be capable of engaging the whole. Content of langi1age in order to arrive at the being that language helps bring to expression. The essential linguistically of understanding expresses itself less in our statements than in our search for the language to say what we have on our minds and hearts. For he11neneutics, it is less constitutive that understanding is expressed in language which is true but trivial than that it lives in the unending process of "summoning the word" and the search for a sharable language. Indeed, understanding is to be conceived as this process, for this process the corresponding realization of the inner word is what grounds the universality of hermeneutics (Grondin 1994, 120). 
Now it is the time to based on linguistic aspects of event of understanding explain Gadamer philosophical hermeneutics features superior to Wittgenstein late philosophy.

\section{Comparison-Gadamer and Wittgenstein}

In language game, Wittgenstein fails to take into account the interaction between the individual and rules. This gives the language a static nature. Interaction can probably be replaced with hermeneutic circle for this is what bestowing dynamic to language in Gadamer's collection of thoughts.

Wittgenstein takes into account merely the rules which are based on language collective consent but considers neitherdynamically historic issues nor reflective aspect of language developing new meanings. This is the missing part in the model proposed by Wittgenstein and which Gadamer highlights. For Gadamer treats tradition as thestream encompassing all aspects of understanding from past to present and to, a historical movement, future.

If, according to Wittgenstein, faculty of language depends on conventional rules which, in turn, depend on epistemological theories, where does the foundation of language lie?

The hermeneutic favored by Gadamer refutes the existence of convention limitations. Yet, it reveals the fundamental historicity of understanding as the presupposition of language consent. Drawing a comparison between the language game offered by Wittgenstein and the horizon of Gadamer, one may understand that adopting a historical perspective, Gadamer acquires an understanding of the relation between rules and their function. It should be noted that despite the discrepancies language games feature, they share a fundamental unity. This rises from historicity of understanding manifested in language.

In other words, participating in the language game, one can acquire the ability to implement its grammar. Function is a two-way road where meaning is expressed and interpreted. Thus, it can be claimed that a language game, a religious culture, calls for such a relation in order to contribute to another culture and take part in its game.

Each language user takes up a particular position within the language. Horizon is culturally obtained and develops to the socio-linguistic environment already interpreted and structured, to the point where one acquires a range of abilities through basic and language-forming confrontations. Concentration on the element of "limitation" in this comparison would alter language game to horizon. While Wittgenstein considers the function of language within the structured limitation of the function, the major attribute of the hermeneutic proposed by Gadamer is the development of language horizons within the flowing context of traditions and cultures.

In the everydayness of articulation and dialogue, horizons meet and interact. To accommodate another horizon, be it another language-user or a text, the speaker ceaselessly interrogates and interprets what is being said. Ultimately, for Gadamer, all authentic use of language involves interpretation as one both seeks to understand and be understood. Interpretation (and translation) are not reproductive acts, they are productive and hence creative (Lawn 2004, 96). Part of dynamic of language is formed by its interpretability which, as a result of development of horizons and through moving back and forth to various horizons, bestows an ever-developing form to language. This is what referred to in the initial part of the paper; the other dynamic factor, playfulness embedded in the nature of language (play). 


\section{Dialogue Welcomed in Islam}

Language accounts for one major element of Wittgenstein's late philosophy and Gadamer's philosophical hermeneutics. Language, along with social convention and lifestyle, is one of the main elements of culture, too.

Wittgenstein understands language through interpreting it as the major element of culture. Each culture has its own rules separating it from other cultures. Gadamer, on the other hand, regards language dynamic. This dynamic taking place as a result of dialogue enables the horizons to develop. This model leads to a dialogue between various religious cultures. And this is exactly what outweighing the model offered by him to that of Wittgenstein, dynamic.

Now, given the Islamic doctrine, the dialogue-based model of Gadamer can be thought to be comparable with the religious culture some verses in the Holy Quran refer to. In numerous cases, Muslims are invited to listen to followers of other religions. A Muslim is but a person seeking the truth in other cultures, traditions, and language worlds, even in remote horizons. The boundary of truth to him extends beyond his own language game, religion and exclusive terrestrial world. He is invited to make a dialogue, choose the best diction, and seek the truth of the world and human regardless of geographical boundaries.

This quest for the truth is the subject of numerous versus in the Holy Quran. It seems no big claim that the Holy Quran is founded on the structure of dialogue. The verses initially descended to Mohammad possesses such a feature. Mohammad is the addressee and the speaker is the angel explaining God's attributes to him in Ghar-e-Hira, the cave. In Al-Fatiha, the first surat in the Holy Quran, human himself is the speaker, the one God's Word is told by. In other words, God's Word comes out of human's mouth; his voice reveals God's Word. Generally, dialogues in the Holy Quran fall into three categories.

\subsection{Addressee-Based Dialogues}

Numerous dialogues are exchanged between two speakers or more, dialogues among God, messengers and angels, and sometimes between God and human. Some dialogues are also exchanged between messengers and their people.

Dialogue among Noah, Moses, and Abraham and their people:

And (we also saved) Abraham: behold, he said to his people, "Serve Allah and fear him: that will be best for you-if ye understand!" (Quran 23:36)

Dialogues between believers and hypocrites:

The day will the hypocrites-men and women-say to the believers: "Wait for us! Let us borrow (a light) from your light!" It will be said: “Turn ye back to your rypear! Then seek a light (where ye can)!” So a wall will be put up betwixt them, with a gate therein (Quran 57:13).

Dialogues human makes with himself; self-talk, reflection and contemplation:

Those surats starting with "call to mind" invite people to deeply reflect. Some surats culminate with "Will ye not (yourselves) be admonished?” Will ye not understand? Or "Will ye then consider not?”

\subsection{Approach-Based Dialogues}

Those surats starting with "sayand tell" contain cultural dialogues. When it is said to them: "Make not mischief on the earth.” They say: "We are only ones that put things right” (Quran 2:11). Generally, the instances of such dialogues are as follows. 


\subsubsection{Proclamation Dialogues}

Some verses contain proclamation signs. Preaches of God were sent through these by messengers to people. 0 Messenger! proclaim The (Message) which hath been Sent to thee from thy Lord. If thou didst not, thou Wouldst not have fulfilled And proclaimed His Mission. And Allah will defend thee From men (who mean mischief). For Allah guideth not Those who reject Faith (Quran 5:67). Furthermore, facing the refusal and denial by his opponents, the messenger introduced himself as the preacher. I but convey to you the messages of my Lord: I am to you a sincere and trustworthy adviser (Quran 7:68). Preaching and conveying God's messages are of such importance that some surats contain this idea that messengers are but to carry the responsibility of preaching and conveying God's doctrine. Of messengers but to preach the clear message? (Quran 16:35)

\subsubsection{Guiding Dialogues}

Dialogue is of no effect unless it is void of violence, insult, and stubbornness-provoking signs amongst others. God has repeatedly asked the messenger to kind-heartedly and instructively give his people advice adopting the most pleasant to address them. The leniency of the intonation, then, would be consistent with the message conveyed.

Invite (all) the way of thy Lord with wisdom and beautiful preaching; and argue with them in ways that are best and most gracious: for thy Lord knoweth best, who have strayed from his path, and who receive guidance (Quran 16:135).

\subsubsection{Requestive Dialogues}

Some verses in the Holy Quran contains inquiries made by people to the messenger about their life concerns and his responses. Of these are the ones with the expressions such as "ask" or "request." Furthermore, there are some verses where "tell" is used. It implies that there existed questions both asked and unasked whose answers are given there. So it can be claimed that God has answered even the questions that were raised in people's mind without their bringing them up.

They ask thy instruction concerning the women Say: Allah doth instruct you about them: and (remember) what hath been rehearsed unto you in the book, concerning the orphaned women to whom ye give not the portions prescribed, and yet whom ye desire to marry, as also concerning the children who are weak and oppressed: that ye stand firm for justice to orphans. There is not a good deed which ye do, but Allah is well-acquainted therewith (Quran 4:127).

\subsubsection{Reasoning Dialogues}

They form the most important dialogues. For they have been highlighted in numerous verses. Addressees are invited to reasoning after which they become convinced.

Say: "Produce your proof if ye are truthful” (Quran 2:111).

God, employing such dialogues, asking his addressees to present their arguments connotes their falseness. That is why "If ye are truthful" is overly used in the Holy Quran.

Employing reasoning, the Holy Quran seeks to back up its claims.

If there were, in the heavens and the earth, other gods besides Allah, there would have been ruin in both! But glory to Allah, the Lord of the throne: (high is he) above what they attribute to him! (Quran 21:22)

\subsubsection{Sensual Dialogues}

God has encouraged the use of senses in some verses. To distinguish monotheists from atheists, for instance, he says, "Are the blind equal with those who see? Or the depths of darkness equal with light?" Or do they assign to Allahl partners who have created (anything) as he has created, so that the creation seemed to 
them similar? Say: "Allah is the creator of all things: He is the one, the supreme and irresistible" (Quran 13:16). Once Moses was to lose patience upon his people taunting and committing obstruction, he took advantage of their emotions and feelings.

And remember, Moses said to his people: "0 my people! Why do ye vex and insult me, though ye know that I am the messenger of Allah (sent) to you?" Then when they went wrong, Allah let their hearts go wrong. For Allah guides not those who are rebellious transgressors (Quran 61:5).

\subsubsection{Persuasive Dialogues}

Certain verses in the Holy Quran take advantage of persuasion for deduction and reasoning. They pose questions in such a way that people cannot but acknowledge the truth.

If indeed thou ask them who has created the heavens and the earth and subjected the sun and the moon (to his law), they will certainly reply, "Allah." how are they then deluded away (from the truth) (Quran 29:61) and if indeed thou ask them who it is that sends down rain from the sky, and gives life therewith to the earth after its death, they will certainly reply, "Allah!” say, "praise be to Allah!” but most of them understand not (Quran 29:63).

\subsection{Subject-Based Dialogues}

Since Islam addresses those potentially tractable, any subject relevant to human and his perfection is included.

Cultural dialogues in Islam fall into the following categories.

5.3.1. Dialogues on Monotheism and Polytheism Negation

0 ye people! Worship your guardian Lord, who created you and those who came before you that ye may become righteous (Quran 2:31).

Say: He is Allah, the one (Quran 112:1).

Say: 0 ye that reject faith! I worship not that which ye worship (Quran 109:1-2).

5.3.2. Dialogues on Resurrection, Reward, Punishment, Heaven, and Hell

The dialogues God opens to both believers and non-believers regarding the Judgment Day, Resurrection and reward and punishment:

For those who reject their Lord (and cherisher) is the chastisement of hell: and evil is (such) destination (Quran 67:6).

When the event inevitable cometh to pass. Then will no (soul) deny its coming (Quran 56:1-2).

Their abode will be the garden. They ask thee about the hour-when will be its appointed time? (Quran 79:41-42)

5.3.3. Dialogues on the Holy Quran and Its Truth, Attributes, and Distortion Invulnerability

God has confirmed in some verses that the Holy Quran is sent down from himself and also stated its invulnerability to distortion.

Those who reject the message when it comes to them (are not hidden from us). And indeed it is a book of exalted power (Quran 41:41-42).

5.3.4. Dialogues on the Lawfuls, Forbiddens, and Traditions

Of the wisdom of God is his referral to all aspects of human life including the question of lawfulness and unlawfulness. The traditions performed in different eras are also stated in the Holy Quran. 
A ye who believe! Eat of the good things that we have provided for you. And be grateful to Allah, if it is him ye worship. He hath only forbidden you dead meat, and blood, and the nesh of swine, and that on which any other name hath been invoked besides that of Allah. but if one is forced by necessity, without willful disobedience (Quran 2:172-3).

\section{Conclusion}

According to the verses in the Holy Quran and the life of Mohammad, Islam welcomes dialogue. Mohammad is always recommended to kindheartedly and pleasantly make dialogues to people unless they tend to show violence, stubbornness, or animosity. These verses contain very simple language to open discussion with those seeking the truth. The importance of the style to adopt for discussion is stated in the following verse.

And dispute ye not with the people of the book, except in the best way, unless it be with those of them who do wrong but say, we believe in the revelation which has come down to us and in that which came down to you (Quran 29:46).

The logic of dialogue is openly welcomed in Islam. For humans with various fields of knowledge hold various beliefs for whose realization they need to make joint efforts. While the discrepancies need cooperation which is possible through dialogue.

Of the issues Islam openly accepts is dialogue with other religions. It not only invites its own and other religion's followers to get involved in dialogues but also proposes dialogue-based measures. Its leaders hold numerous dialogues with their counterparts of other religions. This is utterly evident in the Holy Quran.

To conclude, the ideal world and culture are based on dialogue. And this culture requires its respective theoretical and philosophical foundations.

\section{Notes}

1. In the first type, "you" falls under the category of others. In the second type, the "I" categorizing others considers his analysis incomplete based on such categorization since the objective and intention of others are not clear.

\section{Works Cited}

Alavinia, S. Marefat Shenasi-e Riazi Wittgenstein va Quine. Tehran: Niloofar, 1380.

Figal, G. The Doing of the Thing Itself: Gadamer's Hermenutics Ontology of Language in the Combridge Companian to Gadamer by Robert J. Dostal. Combridge: Combridge University Press, 2002.

Gadamer, H. G. Truth and Method. London: Continuum, 1975.

Grondin, J. Introduction to Philosophical Hermeneutics. New Haven: Yale University Press, 1994.

---. Hermeneutik. Gottingen: Vandenhoeck \& Ruprecht, 2009.

Lawn, C. Wittgenstein and Gadamer. London: Continuum, 2004.

The Holy Quran. Maddinah: King Fahd Holy Quran Printing Complex, 1410-989.

Wittgenstein, L. Philosophical Investigations. Oxford: Basil Blackwell Ltd., 1958.

Weinsheimer, J. Philosophical Hermeneutics and Literary Theory. New Haven: Yale University Press, 1991. 